\title{
Tumour diameter is not reliable for management of non-secreting pancreatic neuroendocrine tumours
}

\author{
Logan Mills', Panagiotis Drymousis ${ }^{2}$, Yogesh Vashist ${ }^{3}$, Christoph Burdelski $^{3}$, \\ Andreas Prachalias ${ }^{4}$, Parthi Srinivasan ${ }^{4}$, Krishna Menon ${ }^{4}$, Corina Cotoi ${ }^{5}$, \\ Saboor Khan ${ }^{6}$, Judith Cave7, Thomas Armstrong ${ }^{8}$, Martin O Weickert 9 , \\ Jakob Izbicki ${ }^{3}$, Joerg Schrader ${ }^{10}$, Andreja Frilling ${ }^{2}$, John K Ramage ${ }^{1}$ and \\ Raj Srirajaskanthan ${ }^{1}$
}

${ }^{1}$ Institute of Liver Studies, King's College Hospital, London, UK ${ }^{2}$ Department of Surgery and Cancer, Imperial College, London, UK

${ }^{3}$ Department of General, Visceral and Thoracic Surgery, University Medical Center, Hamburg-Eppendorf, Hamburg, Germany

${ }^{4}$ Department of Surgery, King's College Hospital, London, UK

${ }^{5}$ Department of Histopathology, King's College Hospital, London, UK

${ }^{6}$ Department of Surgery, University Hospitals Coventry and Warwickshire, Coventry, UK

${ }^{7}$ Department of Oncology, University Hospital, Southampton, UK

${ }^{8}$ Department of Surgery, University Hospital, Southampton, UK

${ }^{9}$ Department of Endocrinology, University Hospitals Coventry and Warwickshire, Coventry, UK

${ }^{10}$ Departments of Gastroenterology and Department of General, Visceral and Thoracic Surgery, University Medical

Center Hamburg-Eppendorf, Hamburg, Germany

Correspondence

should be addressed

to R Srirajaskanthan

Email

r.srirajaskanthan@nhs.net

\begin{abstract}
Small non-functioning pancreatic NETs ( $p N E T s$ ) $\leq 2 \mathrm{~cm}$ can pose a management dilemma in terms of surveillance or resection. There is evidence to suggest that a surveillance approach can be considered since there are no significant radiological changes observed in lesions during long-term follow-up. However, other studies have suggested locoregional spread can be present in $\leq 2 \mathrm{~cm}$ pNETs. The aim of this study was to characterise the prevalence of malignant features and identify any useful predictive variables in a surgically resected cohort of pNETs. 418 patients with pNETs were identified from 5 NET centres. Of these 227 were included for main analysis of tumour characteristics. Mean age of patients was 57 years, $47 \%$ were female. The median follow-up was 48.2 months. Malignant features were identified in $38 \%$ of $\leq 2 \mathrm{~cm}$ pNETs. ROC analysis showed that the current cut-off of $20 \mathrm{~mm}$ had a sensitivity of $84 \%$ for malignancy. The rate of malignant features is in keeping with other surgical series and challenges the belief that small pNETs have a low malignant potential. This study does not support a $20 \mathrm{~mm}$ size cut-off as being a solitary safe parameter to exclude malignancy in pNETs.
\end{abstract}
Key Words
- neuroendocrinology
- endocrine cancers
- gastrointestinal tract
- pancreas
- surveillance

\section{Introduction}

Small pancreatic neuroendocrine tumours pose a management dilemma between surveillance and resection due to the uncertain natural history of these tumours. The case for surveillance in tumours $\leq 2 \mathrm{~cm}$ is supported by European Neuroendocrine Tumour Society
(ENETS) guidelines that state 'A conservative approach seems to be safe as the majority of the observed tumours did not show any significant changes during follow-up' (1). A recent systematic review (2) of studies including a surveillance cohort also concludes that this strategy is

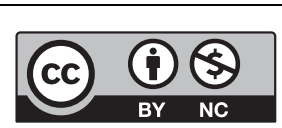

This work is licensed under a Creative Commons Attribution-NonCommercial 4.0 International License. 
safe for selected cases, with fewer than $10 \%$ of tumours demonstrating growth during surveillance $(3,4,5,6,7,8)$. Additionally, autopsy series show that the prevalence of pNETs may be as high as $1-3 \%$, adding weight to the case for surveillance of small asymptomatic lesions $(9,10)$. Finally, surveillance is strongly supported by evidence and guidelines for MEN1 and VHL tumours $\leq 2 \mathrm{~cm}$, which may be encouraging the practice in sporadic tumours $(1,11)$. Variation and controversy exist as to the specific criteria used to select patients for surveillance, and as to the best strategy for using imaging for surveillance.

The case for surgery in all non-functional tumours $\leq 2 \mathrm{~cm}$ does not have specific support in guidelines, but the WHO changed its classification of pNETs from 2004 to 2010 to now state that all pNETs have malignant potential (12). Evidence supporting a surgical approach for tumours $\leq 2 \mathrm{~cm}$ comes from a variety of institutional surgical series and national databases that report malignant features in small, sporadic, asymptomatic tumours. Metastatic disease to the liver is reported in up to $10 \%$ of cases from $\leq 2 \mathrm{~cm}$ surgical series $(5,6,13,14)$. Nodal involvement is reported in up to $14 \%$ of cases $\leq 2 \mathrm{~cm}$, but the impact of nodal involvement on future metastasis or overall survival is debated $(15,16,17,18,19)$. The lack of validated, reliable predictors of malignancy, such as serum markers or radiological features, makes the case for surgery stronger at the present time.

The aim of this study is to use a cohort of resected, nonfunctional, sporadic tumours from five centres that do not routinely adopt surveillance in order to characterise the prevalence of malignant features and identify any useful predictive variables.

\section{Materials and methods}

\section{Patient selection}

The study was designed as a multicentre, retrospective surgical cohort review. Patients were selected using the local NET databases of four UK ENETS Centres of Excellence and the University Hospital of Hamburg. Inclusion criteria were: (1) histopathological diagnosis of pancreatic neuroendocrine tumour; (2) surgical resection of primary tumour before 2014; (3) all stages and grades of disease. Specific exclusion criteria were used: (1) familial syndromes including MEN1, von Hippel Lindau and tuberous sclerosis; (2) patients with syndromes secondary to functionally active pNETs; (3) patients that did not receive resection of their pancreatic primary with curative intent; (4) for analysis of survival, an additional exclusion criterion of patients with less than 12 months of follow-up was applied. Ethical approval was granted from the University of Warwick Biomedical and Scientific Ethics Committee (REGO-2015-1675).

\section{Data collection}

Patient notes were reviewed for relevant variables, and data were collated between centres using a standardised Microsoft Access v16 database. Tumour diameter, morphology and immunohistochemical staining were all recorded from resected surgical specimens reported by dedicated NET pathologists. Tumours were defined as having features suggestive of malignancy if they displayed any of the following: local invasion, vascular invasion, lymph node metastasis or distant metastasis (synchronous or metachronous). Tumours were staged according to the ENETS TNM system for pancreatic neuroendocrine tumours (20). Where staining with the Ki67 antigen was available, grading was assigned using the WHO 2010 system (21). Peri-operative mortality was defined as death within 30 days of surgery; analysis of surgical morbidity was not possible because of heterogeneity of recorded data between centres. Samples were exclusively derived from surgical procedures that were performed for clinical reasons and usual consent procedures were in place.

\section{Follow-up and outcomes}

Patients were followed up with cross-sectional imaging and outpatient appointments for a minimum of 12 months. Median follow-up was calculated using the reverse KaplanMeier method (22). All-cause mortality was confirmed for UK patients using a national register of death. Progressive disease was defined using a composite outcome of local recurrence, progression of pre-operatively diagnosed liver metastases or a new diagnosis of distant metastasis.

\section{Statistical analysis}

Data were described as mean values with standard deviation (s.D.). Comparison between groups was performed using $\chi^{2}$ or the Fisher exact test for categorical data and unpaired $t$-tests or Wilcoxon rank-sum test for continuous variables. Overall survival and progressionfree survival (PFS) were calculated using the Kaplan-Meier method with time calculated from surgical date, and Cox regression analyses were used to determine the impact 
of variables on survival. $P$ values $<0.05$ were considered significant. Analysis was conducted using IBM's SPSS, v22.

\section{Results}

Databases revealed 418 patients with pNETs of whom 227 were included for the main analysis of tumour characteristics according to the reported inclusion and exclusion criteria. The majority of excluded cases did not have surgery performed or only debulking surgical procedures were performed (Fig. 1). Due to duration of follow-up < 12 months, 34 patients were excluded from survival analysis leaving a cohort of 193 patients with a median follow-up of survivors of 48.2 months and by reverse Kaplan-Meier method, 60.9 months (22).

Patients had a mean age of $57,47 \%$ were female and 54\% received surgery before 2010; there was no statistical difference for these variables between patients with tumours $\leq 2 \mathrm{~cm}$ or $>2 \mathrm{~cm}$ (Table 1 ). Larger tumours were significantly more likely to originate from the tail of the pancreas $(P=0.009)$ and to present with distant metastases $(P=0.001)$.

Full pre-operative work-up data were not available from all sites. However, full data were available from two centres, representing 35 of the 66 patients with tumours $<2 \mathrm{~cm}$. As part of work-up, 31 (89\%) patients received CT imaging, 11 (31\%) MRI, 20 (57\%) Octreoscan, 4 (11\%) gallium dotatate and 17 (49\%) endoscopic ultrasound. Of this subgroup of patients, 8 (23\%) had surgically verified lymph node involvement. Pre-operative imaging detected lymph node involvement in three of these cases, in two cases visible on CT and in one case visible on MRI. In the 5 cases where imaging failed to detect lymph nodes, only one patient had received a pre-operative MRI, the remainder receiving a mixture of $\mathrm{CT}$, endoscopy and octreoscan.

Surgical procedure did not vary significantly by tumour diameter group, but enucleations were more common in tumours $\leq 2 \mathrm{~cm}$ (Table 2). Pancreatic head surgery (Whipple's, PPPD or DPP) was performed in 31 (47\%) patients with tumours $\leq 2 \mathrm{~cm}$ compared to $37 \%$ of larger tumours, suggesting that pancreatic head pathology was not viewed as a relative contraindication to surgery even for small asymptomatic tumours. There were 4 cases of perioperative mortality, all following Whipple's procedures performed before 2010 for tumours $>2 \mathrm{~cm}$. 168 (82\%) patients had R0 surgical margins; those that were $\mathrm{R} 1 / \mathrm{R} 2$ included two enucleations for tumours $\leq 2 \mathrm{~cm}$.

Tumours $>2 \mathrm{~cm}$ were significantly more likely to have local invasion, vascular invasion, nodal involvement, distant metastasis or higher grade morphology $(P<0.001)$.

Malignant features were observed in $38 \%$ of tumours $\leq 2 \mathrm{~cm} .12$ (18\%) tumours had invaded locally, typically the common bile duct or duodenum. 13 (20\%) tumours had nodal involvement. There were 10 cases of liver metastases present at diagnosis, of whom 2 had additional peritoneal deposits and 1 developed bone metastasis to the humerus after surgery. Additional characteristics of tumours $\leq 2 \mathrm{~cm}$ with liver metastases were that $7 / 10$ had negative nodes,

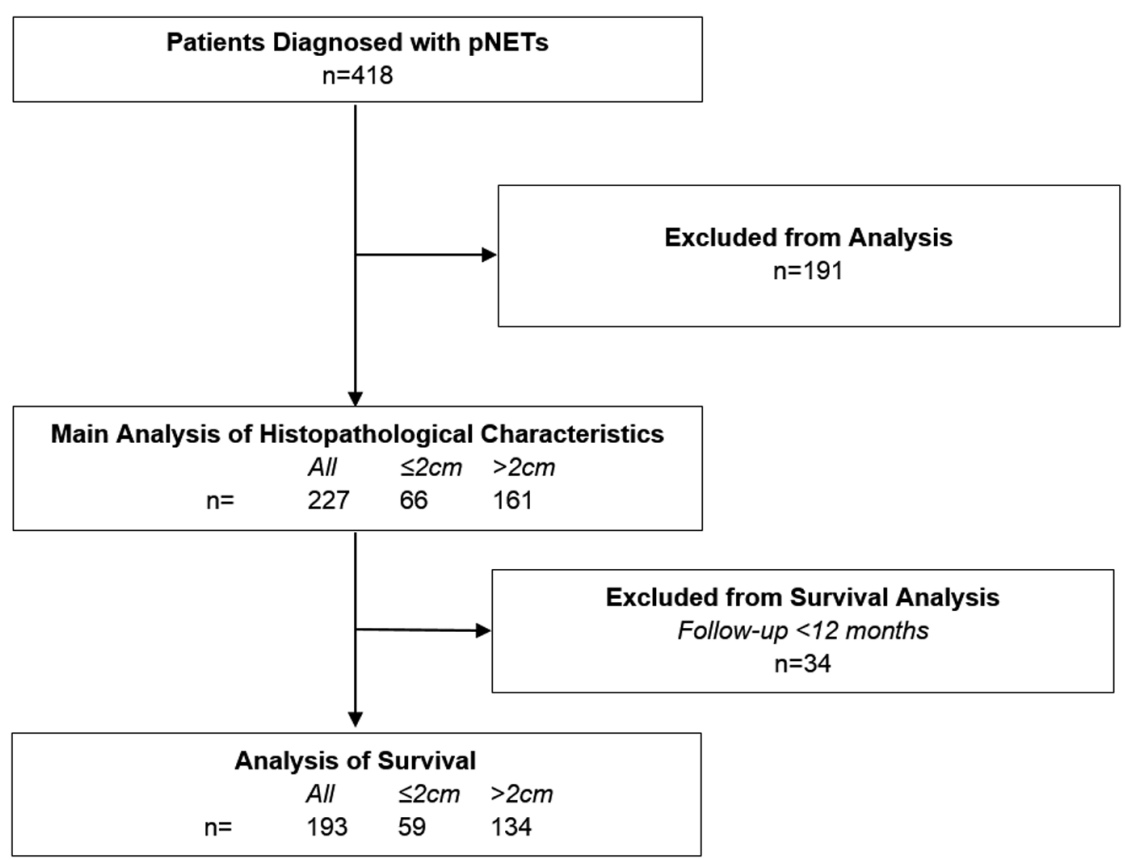

Figure 1

Selection of patients for inclusion in the study. Exclusion criteria, as detailed in the methods, included: (1) familial syndromes including MEN1, von Hippel Lindau and tuberous sclerosis; (2) patients with syndromes secondary to functionally active pNETs; (3) patients that did not receive resection of their pancreatic primary with curative intent. http://www.endocrineconnections.org DOI: 10.1530/EC-17-0293 (c) 2017 The authors Published by Bioscientifica Ltd

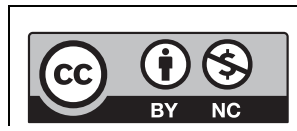

This work is licensed under a Creative Commons Attribution-NonCommercial 4.0 International License. 
Table 1 Demographics and pre-operative characteristics of patients.

Age
Female gender
Surgery pre-2010
Location
$\quad$ Head
Body
Tail
Synchronous distant metastases
Extrahepatic metastases

\begin{tabular}{c}
$\leq \mathbf{2} \mathbf{c m}$ \\
\hline 66 \\
$56(12)$ \\
$36(55 \%)$ \\
$32(48 \%)$ \\
$31(47 \%)$ \\
$12(18 \%)$ \\
$22(33 \%)$ \\
$10(15 \%)$ \\
$3(5 \%)$ \\
\hline
\end{tabular}

\begin{tabular}{c}
\hline \multicolumn{1}{c}{$\mathbf{c m}$} \\
\hline 161 \\
$58(13)$ \\
$71(44 \%)$ \\
$90(56 \%)$ \\
$55(34 \%)$ \\
$14(9 \%)$ \\
$90(56 \%)$ \\
$60(37 \%)$ \\
$16(10 \%)$ \\
\hline
\end{tabular}

\begin{tabular}{c}
\hline All \\
\hline 227 \\
$57(13)$ \\
$107(47 \%)$ \\
$122(54 \%)$ \\
\\
$86(38 \%)$ \\
$26(11 \%)$ \\
$112(49 \%)$ \\
$70(31 \%)$ \\
$19(8 \%)$ \\
\hline
\end{tabular}

$\boldsymbol{P}(\leq 2$ vs $>2)$

Continuous variables described as mean (SD) and categories as count (\%). Differences between groups are tested using unpaired $t$-tests and Fisher's exact test. ${ }^{*} P<0.05 ; * * P<0.005$.

5/10 had grade 1 histology and the smallest tumours were $10 \mathrm{~mm}$. Figure 2 and Table 3 demonstrate that whilst malignancy is predicted by increasing diameter across all tumour sizes (OR 1.09), when only considering tumours $\leq 2 \mathrm{~cm}$ diameter is not correlated with malignant features. ROC analysis showed that the current $20 \mathrm{~mm}$ cut-off had a sensitivity of $84 \%$ for malignancy (AUC 0.823), $15 \mathrm{~mm}$ a sensitivity of $91 \%$ and $10 \mathrm{~mm} 97 \%$.

Table 2 Histopathological results of resected pNETs.

\begin{tabular}{l}
\hline \\
Surgery \\
Whipple's \\
Distal pancreatectomy \\
Enucleation \\
Other \\
Liver resection \\
30 -day mortality \\
Margin \\
R0 \\
R1 \\
R2 \\
Diameter \\
Local invasion \\
Vascular invasion \\
Nodal metastasis \\
Lymph node ratio \\
0 \\
$0-0.2$ \\
$>0.2$ \\
ENETS stage \\
I \\
II \\
III \\
IV \\
Malignant \\
Ki67\% features \\
WHO 2010 grade \\
G1 $\leq 2 \%$ \\
G2 $3-20 \%$ \\
G3>20\% \\
CgA ${ }^{\mathrm{d}}$ elevated \\
Metachronous metastases \\
\end{tabular}

\begin{tabular}{c}
\hline$\leq \mathbf{c m}$ \\
\hline 66 \\
$31(47 \%)$ \\
$30(45 \%)$ \\
$5(8 \%)$ \\
0 \\
$2(3 \%)$ \\
0 \\
$53(88 \%)$ \\
$5(8 \%)$ \\
$2(3 \%)$ \\
$14.7(5)$ \\
$12(18 \%)$ \\
$9(14 \%)$ \\
$13(20 \%)$ \\
$51(77 \%)$ \\
$1(2 \%)$ \\
$3(5 \%)$ \\
$39(59 \%)$ \\
$6(9 \%)$ \\
$11(17 \%)$ \\
$10(15 \%)$ \\
$25(38 \%)$ \\
$4(5)$ \\
$42(64 \%)$ \\
$20(30 \%)$ \\
$2(3 \%)$ \\
$4(24 \%)$ \\
$1(2 \%)$ \\
\\
\\
\\
\\
\\
\\
\end{tabular}

\begin{tabular}{c}
\hline$>2 \mathbf{c m}$ \\
\hline 161 \\
$52(32 \%)$ \\
$103(64 \%)$ \\
$3(2 \%)$ \\
$3(2 \%)$ \\
$29(18 \%)$ \\
$4(2 \%)$ \\
$115(79 \%)$ \\
$20(14 \%)$ \\
$10(7 \%)$ \\
$51.8(33)$ \\
$117(73 \%)$ \\
$61(38 \%)$ \\
$70(43 \%)$ \\
$79(49 \%)$ \\
$10(6 \%)$ \\
$27(17 \%)$ \\
0 \\
$57(35 \%)$ \\
$43(27 \%)$ \\
$60(37 \%)$ \\
$140(87 \%)$ \\
$10(17)$ \\
$62(39 \%)$ \\
$67(42 \%)$ \\
$24(15 \%)$ \\
$26(47 \%)$ \\
$18(18 \%)$ \\
\\
\hline 10$)$ \\
\\
\end{tabular}

\begin{tabular}{c}
\hline All \\
\hline 227 \\
$83(37 \%)$ \\
$133(59 \%)$ \\
$8(4 \%)$ \\
$3(1 \%)$ \\
$31(14 \%)$ \\
$4(2 \%)$ \\
$168(82 \%)$ \\
$25(12 \%)$ \\
$12(6 \%)$ \\
$40.4(32)$ \\
$129(57 \%)$ \\
$70(31 \%)$ \\
$83(37 \%)$ \\
$130(57 \%)$ \\
$11(5 \%)$ \\
$30(13 \%)$ \\
$39(17 \%)$ \\
$63(28 \%)$ \\
$54(24 \%)$ \\
$70(31 \%)$ \\
$165(73 \%)$ \\
$8.01(15)$ \\
$104(46 \%)$ \\
$87(38 \%)$ \\
$26(11 \%)$ \\
$30(42 \%)$ \\
$19(8 \%)$ \\
\end{tabular}

$\boldsymbol{P}(\leq 2$ vs $>2)$

0.351

0.188

$0.009 *$

$0.001 * *$

0.290

aWhipple's category includes pylorus-preserving pancreatoduodenectomies and duodenum preserving pancreatectomies; blymph node ratio= positive nodes/nodes sampled; ' malignant features are defined as local invasion, vascular invasion, lymph node metastasis or distant metastasis (synchronous or metachronous); ${ }^{\mathrm{d}} \mathrm{CgA}=$ chromogranin $\mathrm{A} .{ }^{*} P<0.05 .{ }^{*} P<0.005$.

\begin{tabular}{|lr}
\hline http://www.endocrineconnections.org & ○ 2017 The authors \\
DOI: $10.1530 /$ EC-17-0293 & Published by Bioscientifica Ltd
\end{tabular}


100

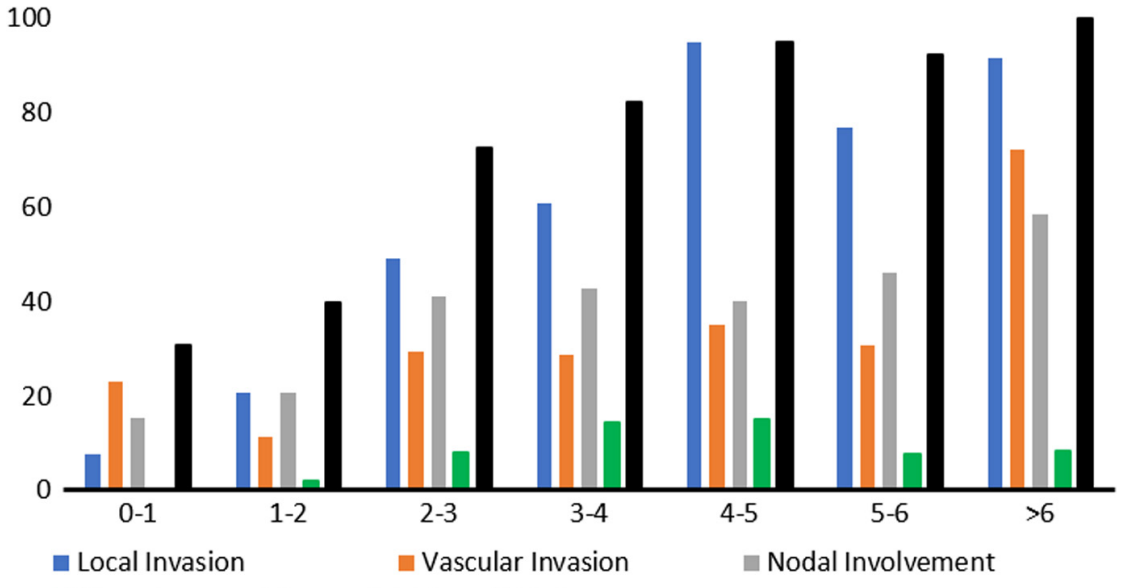

Figure 2

Metachronous Metastasis Overall Malignancy

Prevalence of malignant features (\%), stratified by tumour diameter $(\mathrm{cm})$.

Patients with >12-month follow-up experienced a median overall survival of 202 months with no significant difference between tumours $\leq 2 \mathrm{~cm}$ and $>2 \mathrm{~cm}$ (Table 4 ). However, as demonstrated by Fig. 3 , tumours $\leq 2 \mathrm{~cm}$ experienced initial mortality similar to tumours $>2 \mathrm{~cm}$, followed by stable survival of $87 \%$ for 10 years. In 4 of these 8 cases, death was attributable to surgical complications, but at greater than 30 days. The specific cause is not known for the remaining 4 cases, but 2 had known liver metastases. Significant prognostic factors included stage, grade and extrahepatic disease; grade and extrahepatic disease remained significant in multivariate analysis after correcting for age and year of surgery (Table 5).

Progression was defined by local recurrence, new or progressive metastases or death (Table 4 ). The 11 cases of local recurrence were associated with involved margins (OR 4.62, $P=0.038$ ). Median PFS was significantly better for tumours $\leq 2 \mathrm{~cm}$ (139 vs 47.7 months; $P=0.002$ ). Stage, grade, diameter, vascular invasion, nodal metastases, distant metastasis, involved margins and elevated $\mathrm{CgA}$ were all predictive of progression (Table 5). In a multivariate model diameter (HR 1.011), grade (HR 2.68) and margin involvement (HR 2.581) remained significant after correcting for gender. Subgroup analysis of tumours $\leq 2 \mathrm{~cm}$ was insignificant for overall survival given the rarity of events, but analysis of PFS mirrored results of the

Table 3 Logistic regression of various variables' abilities to predict malignant features.

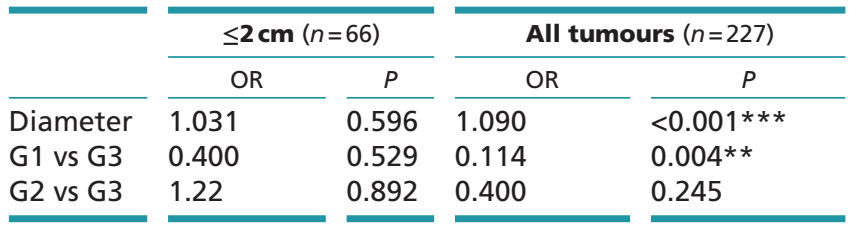

OR=odds ratio. ${ }^{*} \mathrm{P}<0.05 ; * * \mathrm{P}<0.005 ; * * * \mathrm{P}<0.001$.

http://www.endocrineconnections.org

DOI: 10.1530/EC-17-0293

C) 2017 The authors Published by Bioscientifica Ltd whole cohort with grade, stage and extrahepatic disease remaining significant factors.

\section{Discussion}

This study has demonstrated that tumours $\leq 2 \mathrm{~cm}$ can have malignant characteristics including nodal and distant metastatic disease. More importantly the overall survival of the $\leq 2 \mathrm{~cm}$ vs $>2 \mathrm{~cm}$ cohort is not significantly different suggesting that the biology of these tumours is not altogether that different.

The natural history of these sporadic, incidental tumours is not well understood but would be studied in an ideal world with a prospective, cross-sectional cohort study with decades of follow-up and tissue diagnosis. Without a robust understanding of the natural history, it is consequently difficult to establish specific criteria for a surveillance management strategy. This would require a

Table 4 Outcomes for 193 patients with >12-month follow-up.

\begin{tabular}{|c|c|c|c|c|}
\hline & $\leq 2 \mathrm{~cm}$ & $>2 \mathrm{~cm}$ & All & $\boldsymbol{P}(\leq 2$ vs $>2)$ \\
\hline$N$ & 59 & 134 & 193 & \\
\hline 30-day mortality & 0 & $3(2 \%)$ & $3(2 \%)$ & 0.332 \\
\hline Recurrence & $1(2 \%)$ & $10(7 \%)$ & $11(6 \%)$ & 0.099 \\
\hline $\begin{array}{l}\text { Metachronous } \\
\text { metastasis }\end{array}$ & $1(2 \%)$ & $25(19 \%)$ & $26(13 \%)$ & $<0.001$ *** \\
\hline Median follow-up & 47.6 & 62.8 & 60.9 & $0.036 *$ \\
\hline PFS median & 139 & 47.7 & 57.9 & $0.002 * *$ \\
\hline \multicolumn{5}{|l|}{ Overall survival } \\
\hline Median & 202.2 & 150.9 & 202.2 & 0.122 \\
\hline 5 year & $87 \%$ & $75 \%$ & $78 \%$ & \\
\hline 10 year & $87 \%$ & $51 \%$ & $59 \%$ & \\
\hline
\end{tabular}

Progression-free (PFS) and all-cause mortality are presented as median survival in months from surgery. Comparisons are made using Fisher's exact test or the log-rank test. ${ }^{*} P<0.05 ;{ }^{*} P<0.005 ;{ }^{* * *} P<0.001$.

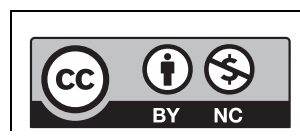

This work is licensed under a Creative Commons Attribution-NonCommercial 4.0 International License. 


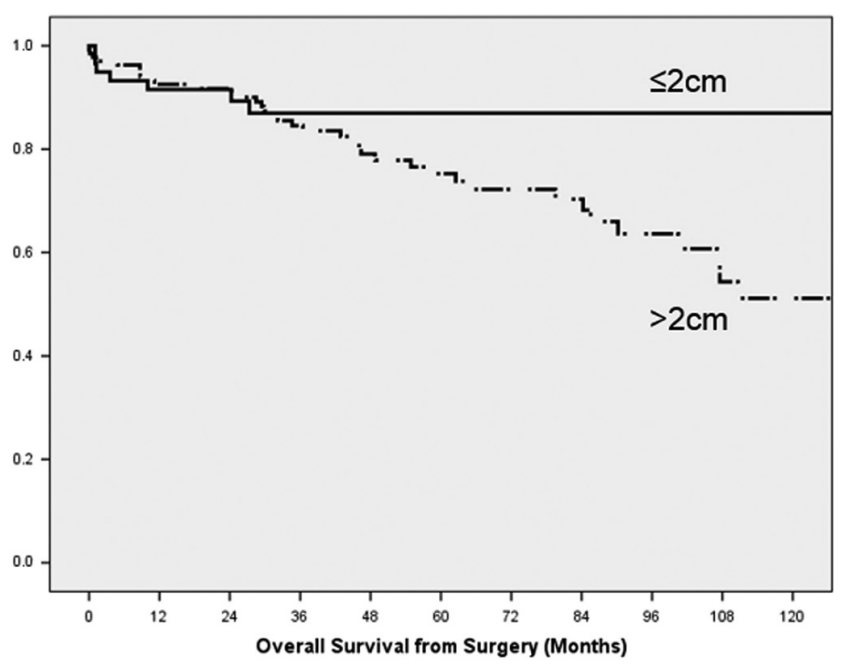

Figure 3

Kaplan-Meier survival curves of 193 patients with >12-month follow-up, stratified by tumour diameter. The difference in median survival was not significant $(P=0.122)$.

randomised trial between surgery and surveillance for a high level of evidence. Consequently, a variety of surgical series, reviews of national databases and retrospective observational studies have been performed but are plagued by a variety of methodological limitations. The present study is not free from limitations, but its multicentre approach with an almost exclusively surgical strategy and long follow-up does have advantages. An evaluation of the various strengths and limitations is detailed below.
Median follow-up varies considerably in published observational cohorts, but is rarely more than 44 months and a mean of the medians was only 38.4 months (Table 6). By contrast, the median survival of tumours $\leq 2 \mathrm{~cm}$ in our study was 47.6 months, shorter only than the study by Zhang and coworkers (8). In a tumour group in which metastases have been reported up to 6 years after diagnosis, long-term follow-up is clearly necessary in order to assess the safety (8).

Amongst all published studies of observational cohorts, only 173 (41\%) of patients had a tissue-proven diagnosis of a pNET (Table 6). Only one study reported the use of Gallium-PET scanning in order to improve the accuracy of diagnosis, the remainder using CT appearances only (6). If only half of the tumours undergoing surveillance had malignant potential, then the rate of progression of pNETs undergoing surveillance may have been severely underestimated. By definition, all patients in our surgical series had a tissue-proven diagnosis.

Practices regarding selection for surgery or surveillance vary widely between centres resulting in considerable heterogeneity in the published reports, making application of findings of individual studies difficult. For example, there are many reasons why patients underwent surveillance, including physician decision, patient surgical refusal and comorbid contraindications to surgery. Where these data were available, it was evident that on average only $46 \%$ of eligible patients underwent surgery (Table 6). A further

Table 5 Prognostic variables tested using univariate Cox proportional-hazard analysis.

\begin{tabular}{|c|c|c|c|c|c|c|}
\hline & \multirow{2}{*}{\multicolumn{2}{|c|}{$\frac{\leq \mathbf{2} \mathbf{c m}(n=59)}{\text { PFS }}$}} & \multicolumn{4}{|c|}{ All tumours $(n=193)$} \\
\hline & & & \multicolumn{2}{|c|}{ PFS } & \multicolumn{2}{|c|}{ All-cause mortality } \\
\hline & $\mathrm{HR}$ & $P$ & $\mathrm{HR}$ & $P$ & HR & $P$ \\
\hline Age & 1.020 & 0.426 & 1.005 & 0.546 & 1.038 & $0.006 *$ \\
\hline Female gender & 0.381 & $0.012 *$ & 0.584 & $0.01 *$ & 0.893 & 0.701 \\
\hline Resection > 2010 & 0.629 & 0.167 & 0.727 & 0.185 & 0.421 & $0.015 *$ \\
\hline Diameter & 1.121 & 0.111 & 1.012 & $<0.001 *$ & 1.005 & 0.268 \\
\hline Benign features & 0.723 & 0.231 & 0.327 & $<0.001 *$ & 0.733 & 0.404 \\
\hline Vascular invasion & 2.095 & 0.213 & 2.097 & $0.001 * *$ & & ns \\
\hline N1 & 2.87 & 0.051 & 1.669 & $0.02 *$ & 1.447 & 0.234 \\
\hline LNR $<0.2$ vs $>0.2$ & & ns & 0.816 & 0.686 & 0.565 & 0.141 \\
\hline Metastasis & 2.968 & 0.072 & 2.991 & $<0.001 * * *$ & 2.198 & $0.009 *$ \\
\hline Extrahepatic & 10.797 & $0.001 * *$ & 0.378 & $0.001 * *$ & 4.231 & $<0.001 * * *$ \\
\hline \multicolumn{7}{|l|}{ Stage vs IV } \\
\hline 1 & 0.255 & $0.045^{*}$ & 0.176 & $<0.001 * * *$ & 0.425 & 0.087 \\
\hline II & 0.901 & 0.906 & 0.348 & $<0.001 * * *$ & 0.562 & 0.135 \\
\hline III & 0.396 & 0.234 & 0.407 & $<0.001 * * *$ & 0.402 & $0.018 *$ \\
\hline \multicolumn{7}{|l|}{ Grade vs G3 } \\
\hline G1 & 0.329 & $0.04 *$ & 0.276 & $<0.001 * * *$ & 0.121 & $<0.001 * * *$ \\
\hline G2 & No G3 & & 0.568 & 0.068 & 0.274 & $<0.001 * * *$ \\
\hline R1/R2 Margin & 1.382 & 0.678 & 2.312 & $0.001 * *$ & 1.104 & 0.803 \\
\hline \multicolumn{7}{|c|}{$\begin{array}{l}* P<0.05 ; * * P<0.005 ; * * * P<0.001 \\
\text { HR, hazard ratio; LNR, lymph node ratio; PFS, progression-free survival. }\end{array}$} \\
\hline \multicolumn{2}{|c|}{$\begin{array}{l}\text { http://www.endocrineconnections.org } \\
\text { DOI: 10.1530/EC-17-0293 }\end{array}$} & Publishe & $\begin{array}{l}\text { e authors } \\
\text { tifica Ltd }\end{array}$ & & \multicolumn{2}{|c|}{$\begin{array}{l}\text { This work is licensed under a Creative Commons } \\
\text { Attribution-NonCommercial } 4.0 \text { International } \\
\text { License. }\end{array}$} \\
\hline
\end{tabular}


Table 6 Data extracted from all studies reporting a period of observation of small, non-functioning pNETs.

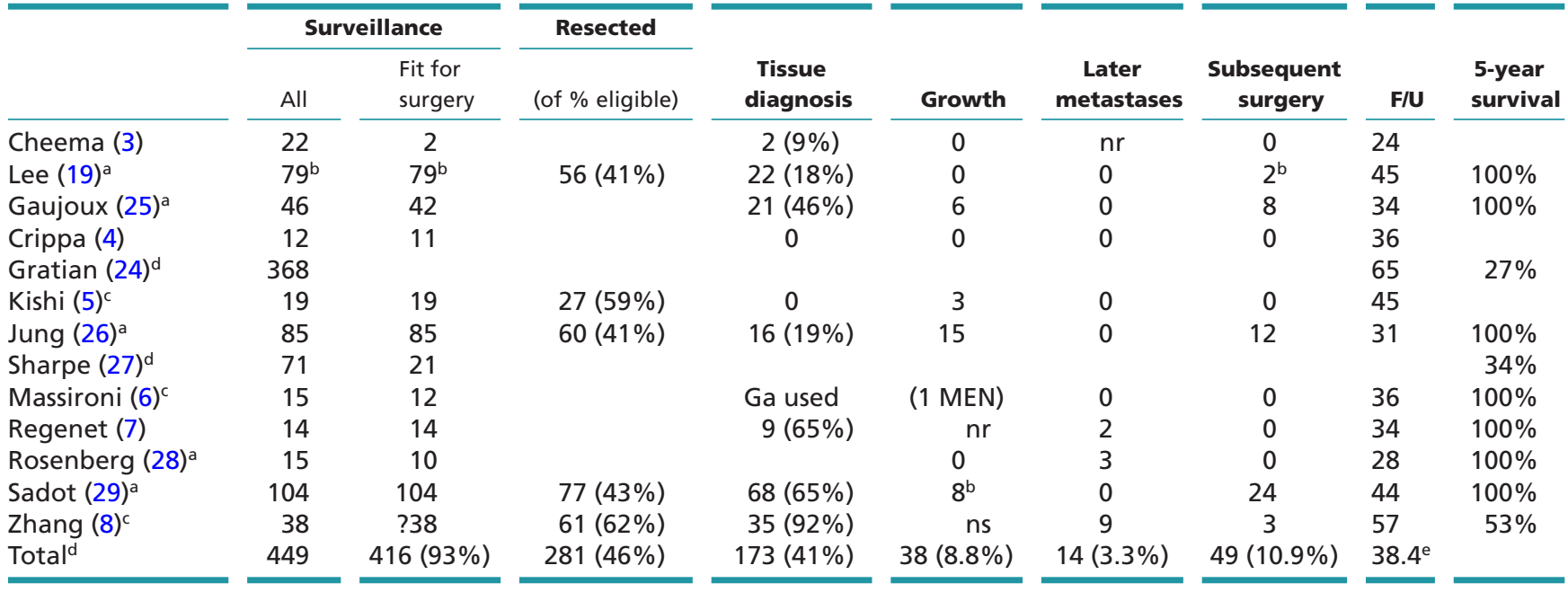

ancluded in the Partelli systematic review (2); b Data extracted from primary studies differing from Partelli review; 'Includes familial syndromes; ${ }^{\mathrm{d}}$ Analyses of national databases; not included in totals due to unreliable coding; ${ }^{\text {eMean }}$ of medians (months).

F/U, Follow-up; nr, not reported; ns, not significant.

source of heterogeneity is that inclusion criteria for surveillance varied between reported observational cohorts, in particular with regards to radiological nodal disease and grade, where known. Finally, criteria used to indicate a need for resection in a patient undergoing surveillance varied. Whilst growth on cross-sectional imaging was universally used, the impact of patient and physician preference on management varied widely. Of note and concern, patients who were observed but later resected were analysed as both surveillance and resection by different studies, making meta-analysis hazardous. This variation in reporting was addressed when constructing Table 6.

Table 7 Data extracted from all studies reporting surgical outcomes specifically for the subgroup of non-functional pNETs $\leq 2 \mathrm{~cm}$.

\begin{tabular}{|c|c|c|c|c|c|c|c|c|}
\hline & $n$ & $\begin{array}{l}\text { Inclusion } \\
\text { criteria }\end{array}$ & N1b & M1 & Local recurrence & $\begin{array}{c}\text { Metachronous } \\
\text { metastases }\end{array}$ & $\mathbf{F} / \mathbf{U}$ & $\begin{array}{l}\text { 5-year } \\
\text { survival }\end{array}$ \\
\hline Haynes (23) & 39 & Asym & & & & 3 & & $92 \%$ \\
\hline Bettini (30) & 51 & R0; Asym & $14 \%$ & 0 & 3 & 0 & 47 & $94 \%$ \\
\hline Lee $(19)^{a}$ & 56 & Mo & $5(9 \%)$ & (0) & 0 & 0 & 52 & $100 \%$ \\
\hline Cherefant (13) & 56 & Asym & 4 & 2 & & 1 & 33 & $96 \%$ \\
\hline Kuo $(14)^{d}$ & 263 & & $6 \%$ & 26 & & & & $82 \%$ \\
\hline Gratian $(24)^{d}$ & 999 & & & & & & 65 & $82 \%$ \\
\hline \multirow[t]{2}{*}{ Kishi $(5)^{c}$} & 27 & & $22 \%$ & 3 & & & & \\
\hline & & & $>19 \mathrm{~mm}$ & $25 \mathrm{~mm}$ & & & & \\
\hline Fischer (16) & 61 & & $12 \%$ & & & 1 & 31 & $95 \%$ \\
\hline Birnbaum (17) & 34 & Asym & 3 & & & & & \\
\hline Jung $(26)^{a}$ & 60 & M0 & & (5) & 0 & 0 & 32 & $100 \%$ \\
\hline Sharpe $(27)^{d}$ & 309 & M0 & & & & & 60 & $82 \%$ \\
\hline Sallinen (18) & 24 & & 4 & 1 & & 3 & 27 & $88 \%$ \\
\hline Massironi (6) & 21 & & & 9 & & & 50 & $90 \%$ \\
\hline Regenet (7) & 66 & & & & & 7 & 34 & $97 \%$ \\
\hline Rosenberg $(28)^{a}$ & 8 & M0; G1/2 & & & 1 & 2 & 34 & \\
\hline Sadot $(29)^{a}$ & 77 & Mo & & & 5 & 0 & 57 & $100 \%$ \\
\hline Zhang (8) ${ }^{c}$ & 61 & & & $10 \mathrm{~mm}$ & & 7 & 57 & $83 \%$ \\
\hline This study & 66 & & 13 & 10 & 1 & 1 & 48 & $87 \%$ \\
\hline Total ${ }^{\mathrm{d}}$ & 707 & & $12.3 \%^{b}$ & $30(9.7 \%)$ & $10(3.1 \%)$ & $23(3.7 \%)$ & & \\
\hline
\end{tabular}

ancluded in the Partelli (2016) systematic review (2); ${ }^{b}$ Nodal involvement as reported, allowance is made where reported for low rates of nodal sampling but the total percentage calculated is therefore a lower estimate; Includes familial syndromes; ${ }^{\mathrm{d} A n a l y s e s}$ of national databases; not included in totals due to unreliable coding.

Asym, asymptomatic presentation; F/U, follow-up; MO, no distant metastases at surgery; R0, uninvolved surgical margin.

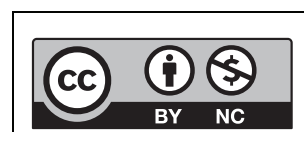

This work is licensed under a Creative Commons Attribution-NonCommercial 4.0 International License. 
Compared to the published literature, we report 25 (38\%) tumours $\leq 2 \mathrm{~cm}$ having malignant features when histopathology was reviewed, suggesting that these small tumours are not benign or indolent. Distant metastases were present in $15 \%$ of cases at presentation, all to the liver. This is in keeping with other surgical series that report a combined rate of metastasis of 9.7\% (Table 7). In this study the smallest diameter of primary with distant metastases was $10 \mathrm{~mm}$, which is also in keeping with other studies that report metastatic diameters of $10 \mathrm{~mm}$ (8) and $25 \mathrm{~mm}$ (5). Thus, using $20 \mathrm{~mm}$ or even $15 \mathrm{~mm}$ as has been suggested as a criterion for surveillance will not guarantee the absence of metastatic disease $(5,7)$.

There was one case $(1.7 \%)$ of liver metastases that developed following surgery in a tumour $\leq 2 \mathrm{~cm}$ in this study. This is in keeping with the surgical literature that reports 23 cases $(3.7 \%)$ in a similar cohort, whilst 14 patients $(3.3 \%)$ in surveillance studies experienced metachronous metastases. Of concern, these cases were difficult to predict. One surveillance study described two cases of metachronous metastasis with no increase in size of the primary, making diameter-based surveillance strategies problematic (7). In the present study, the one case of later metastasis had 2/8 lymph nodes positive, but many cases of metachronous metastases from tumours with negative nodes have been described (23).

In this study $43 \%$ of lymph nodes in tumours $>2 \mathrm{~cm}$ were involved, falling to $20 \%$ in tumours $\leq 2 \mathrm{~cm}$. This compares to $12.3 \%$ on average in other comparable surgical series (Table 7). A review of a national database of tumours $\leq 2 \mathrm{~cm}$ revealed rates of lymph node metastasis as high as $30 \%$ in tumours $<5 \mathrm{~mm}$, but these findings must be questioned given the limitations of national coding variation (24). Limited sampling made calculation of the lymph node ratio difficult. Of interest, nodal involvement was not significantly associated with progression in tumours $\leq 2 \mathrm{~cm}$, making the presence of nodes of equivocal importance when defining management strategy for small tumours. Nodal positivity was not significantly prognostic across all tumours, in keeping with a number of other studies. As described earlier, lymph node metastasis was accurately diagnosed on pre-operative imaging when both CT and MRI were included, and as such, any future surveillance protocol should consider including both modalities as well as considering endoscopy and somatostatin-based imaging.

There are currently two prospective clinical trials underway to help determine the natural history of small pancreatic NETs. The IPANEMA trial (non-functioning small $(\leq 2 \mathrm{~cm})$ neuroendocrine pancreatic incidentaloma;
ClinicalTrials.gov Identifier NCT03022188) aims to determine the natural history of small non-functional tumours observed for a period of three years. The second study ASPEN (a prospective evaluation of the management of sporadic asymptomatic non-functioning pancreatic neuroendocrine neoplasms $\leq 2 \mathrm{~cm}$ ) is a prospective observational study assessing time to progression in patients not undergoing surgery and also time to recurrence in patients who do undergo surgery in small pNETs.

The consideration of surgery in small incidentalomas is not without risk: there is a significant risk of morbidity (around 30\%) and mortality (1-5\%) with surgery especially if undertaking a Whipples procedure. Whilst observation of these tumours may be appropriate in some cases; however, the natural history of these lesions in an individual patient cannot be accurately predicted. Therefore, this does need to be discussed in detail with the patient prior to offering surgery for small incidental non-functional pancreatic NETs. Full staging with cross-sectional imaging, PET imaging and histological confirmation of tumour would help ensure that there is no overt lymph node or metastatic involvement and also the grade of tumour. This could help with the decisionmaking process. Recent advances in contrast-enhanced endoscopic ultrasound could also offer benefit in helping determine the nature of lesions.

The present study has a number of specific limitations. The cause of death was not established for all cases and consequently all-cause mortality was analysed, which may be considerably different from disease-specific mortality. The overall survival data are difficult to interpret since the cause of death is not known in this series. It seems unlikely that all deaths were related to pancreatic NET disease progression. Both asymptomatic, incidental cases as well as symptomatic presentation were included, which may have led to a higher observed prevalence of malignant features than other studies.

\section{Conclusions}

This study demonstrated that up to $38 \%$ of pNETs $\leq 2 \mathrm{~cm}$ display malignant features and that these are not correlated with increasing tumour diameter. This rate of malignant features is in keeping with other surgical series and challenges the belief that small pNETs have low malignant potential. This study does not support $20 \mathrm{~mm}$ as a safe cutoff for malignancy, and indeed no single diameter criteria can be used to define surveillance strategies.

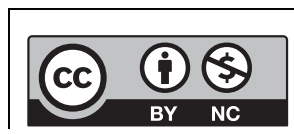

This work is licensed under a Creative Commons Attribution-NonCommercial 4.0 International License. 


\section{Declaration of interest}

The authors declare that there is no conflict of interest that could be perceived as prejudicing the impartiality of the research reported.

\section{Funding}

This research did not receive any specific grant from any funding agency in the public, commercial or not-for-profit sector.

\section{Acknowledgements}

All authors are thanked for their comments and contributions towards the preparation of the manuscript.

\section{References}

1 Falconi M, Eriksson B, Kaltsas G, Bartsch DK, Capdevila J, Caplin M, Kos-Kudla B, Kwekkeboom D, Rindi G, Klöppel G, et al. ENETS Consensus Guidelines update for the management of patients with functional pancreatic neuroendocrine tumors and non-functional pancreatic neuroendocrine tumors. Neuroendocrinology 2016103 153-171. (doi:10.1159/000443171)

2 Partelli S, Cirocchi R, Crippa S, Cardinali L, Fendrich V, Bartsch DK $\&$ Falcon M. Systematic review of active surveillance versus surgical management of asymptomatic small non-functioning pancreatic neuroendocrine neoplasms. British Journal of Surgery 2017104 34-41. (doi:10.1002/bjs.10312)

3 Cheema A, Weber J \& Strosberg JR. Incidental detection of pancreatic neuroendocrine tumors: an analysis of incidence and outcomes. Annals of Surgical Oncology 201219 2932-2936. (doi:10.1245/s10434012-2285-7

4 Crippa S, Partelli S, Zamboni G, Scarpa A, Tamburrino D, Bassi C, Pederzoli P \& Falconi M. Incidental diagnosis as prognostic factor in different tumor stages of nonfunctioning pancreatic endocrine tumors. Surgery 2014155 145-153. (doi:10.1016/j.surg.2013.08.002)

5 Kishi Y, Shimada K, Nara S, Esaki M, Hiraoka N \& Kosuge T. Basing treatment strategy for non-functional pancreatic neuroendocrine tumors on tumor size. Annals of Surgical Oncology 201421 2882-2888. (doi:10.1245/s10434-014-3701-y)

6 Massironi S, Rossi RE, Zilli A, Casazza G, Ciafardini C \& Conte D. A wait-and-watch approach to small pancreatic neuroendocrine tumors: prognosis and survival. Oncotarget 20167 18978-18983. (doi:10.18632/oncotarget.7902)

7 Regenet N, Carrere N, Boulanger G, de Calan L, Humeau M, Arnault V, Kraimps JL, Mathonnet M, Pessaux P, Donatini G, et al. Is the 2-cm size cutoff relevant for small nonfunctioning pancreatic neuroendocrine tumors: a French multicenter study. Surgical 2016 159 901-907. (doi:10.1016/j.surg.2015.10.003)

8 Zhang IY, Zhao J, Fernandez-Del Castillo C, Braun Y, Razmdjou S, Warshaw AL, Lillemoe KD \& Ferrone CR. Operative versus nonoperative management of nonfunctioning pancreatic neuroendocrine tumors. Journal of Gastrointestinal Surgery $2016 \mathbf{2 0}$ 277-283. (doi:10.1007/s11605-015-3043-5)

9 Grimelius L, Hultquist GT \& Stenkvist B. Cytological differentiation of asymptomatic pancreatic islet cell tumours in autopsy material. Virchows Archiv: A, Pathological Anatomy and Histology 1975365 275-288. (doi:10.1007/BF00471177)

10 Kimura W, Kuroda A \& Morioka Y. Clinical pathology of endocrine tumors of the pancreas. Analysis of autopsy cases. Digestive Diseases and Sciences 199136 933-942. (doi:10.1007/BF01297144)

11 de Mestier L, Gaujoux S, Cros J, Hentic O, Vullierme MP, Couvelard A, Cadiot G, Sauvanet A, Ruszniewski P, Richard S, et al. Long-term prognosis of resected pancreatic neuroendocrine tumors in von Hippel-Lindau disease is favorable and not influenced by small tumors left in place. Annals of Surgery 2015262 384-388. (doi:10.1097/SLA.0000000000000856)

12 Bosman F \& Carneiro F. World Health Organization Classification of Tumours, Pathology and Genetics of Tumours of the Digestive System. Lyon, France: IARC Press, 2010.

13 Cherenfant J, Stocker SJ, Gage MK, Du H, Thurow TA, Odeleye M, Schimpke SW, Kaul KL, Hall CR, Lamzabi I, et al. Predicting aggressive behavior in nonfunctioning pancreatic neuroendocrine tumors. Surgery 2013154 783-785. (doi:10.1016/j.surg.2013.07.004)

14 Kuo EJ \& Salem RR. Population-level analysis of pancreatic neuroendocrine tumors $2 \mathrm{~cm}$ or less in size. Annals of Surgical Oncology 201320 2815-2821. (doi:10.1245/s10434-013-3005-7)

15 Bettini R, Partelli S, Boninsegna L, Capelli P, Crippa S, Pederzoli P, Scarpa A \& Falconi M. Tumor size correlates with malignancy in nonfunctioning pancreatic endocrine tumor. Surgery 2011150 75-82. (doi:10.1016/j.surg.2011.02.022)

16 Fischer L, Bergmann F, Schimmack S, Hinz U, Prieß S, MüllerStich BP, Werner J, Hackert T \& Büchler MW. Outcome of surgery for pancreatic neuroendocrine neoplasms. British Journal of Surgery 2014 101 1405-1412. (doi:10.1002/bjs.9603)

17 Birnbaum DJ, Gaujoux S, Cherif R, Dokmak S, Fuks D, Couvelard A, Vullierme MP, Ronot M, Ruszniewski P, Belghiti J, et al. Sporadic nonfunctioning pancreatic neuroendocrine tumors: prognostic significance of incidental diagnosis. Surgery 2014155 13-21. (doi:10.1016/j.surg.2013.08.007)

18 Sallinen V, Haglund C \& Seppänen H. Outcomes of resected nonfunctional pancreatic neuroendocrine tumors: do size and symptoms matter? Surgical 2015158 1556-1563. (doi:10.1016/j. surg.2015.04.035)

19 Lee LC, Grant CS, Salomao DR, Fletcher JG, Takahashi N, Fidler JL, Levy MJ \& Huebner M. Small, nonfunctioning, asymptomatic pancreatic neuroendocrine tumors (PNETs): role for nonoperative management. Surgery 2012152 965-974. (doi:10.1016/j. surg.2012.08.038)

20 Rindi G, Klöppel G, Alhman H, Caplin M, Couvelard A, de Herder WW, Erikssson B, Falchetti A, Falconi M, Komminoth P, et al. TNM staging of foregut (neuro)endocrine tumors: a consensus proposal including a grading system. Virchows Archiv 2006449 395-401. (doi:10.1007/s00428-006-0250-1)

21 Klimstra DS, Modlin IR, Coppola D, Lloyd RV \& Suster S. The pathologic classification of neuroendocrine tumors: a review of nomenclature, grading, and staging systems. Pancreas 201039 707-712. (doi:10.1097/MPA.0b013e3181ec124e)

22 Schemper M \& Smith TL. A note on quantifying follow-up in studies of failure time. Controlled Clinical Trials 199617 343-346. (doi:10.1016/0197-2456(96)00075-X)

23 Haynes AB, Deshpande V, Ingkakul T, Vagefi PA, Szymonifka J, Thayer SP, Ferrone CR, Wargo JA, Warshaw AL \& Fernández-del Castillo C. Implications of incidentally discovered, nonfunctioning pancreatic endocrine tumors: short-term and long-term patient outcomes. Archives of Surgery 2011146 534-538. (doi:10.1001/ archsurg.2011.102)

24 Gratian L, Pura J, Dinan M, Roman S, Reed S \& Sosa JA. Impact of extent of surgery on survival in patients with small nonfunctional pancreatic neuroendocrine tumors in the United States. Annals of Surgical Oncology 201421 3515-3521. (doi:10.1245/s10434-014-3769-4)

25 Gaujoux S, Partelli S, Maire F, D'Onofrio M, Larroque B, Tamburrino D, Sauvanet A, Falconi M \& Ruszniewski P. Observational study of natural history of small sporadic nonfunctioning pancreatic neuroendocrine tumors. Journal of Clinical Endocrinology and Metabolism 201398 4784-4789. (doi:10.1210/jc.2013-2604)

26 Jung JG, Lee KT, Woo YS, Lee JK, Lee KH, Jang KT \& Rhee JC. Behavior of small, asymptomatic, Nonfunctioning Pancreatic Neuroendocrine Tumors (NF-PNETs). Medicine 201594 e983-e983. (doi:10.1097/MD.0000000000000983)

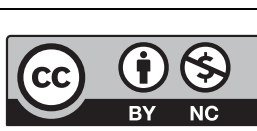

This work is licensed under a Creative Commons Attribution-NonCommercial 4.0 International License. 
27 Sharpe SM, In H, Winchester DJ, Talamonti MS \& Baker MS. Surgical resection provides an overall survival benefit for patients with small pancreatic neuroendocrine tumors, Journal of Gastrointestinal Surgery 201519 117-123. (doi:10.1007/s11605-014-2615-0)

28 Rosenberg AM, Friedmann P, Del Rivero J, Libutti SK \& Laird AM. Resection versus expectant management of small incidentally discovered nonfunctional pancreatic neuroendocrine tumors. Surgical 2016159 302-309. (doi:10.1016/j.surg.2015.10.013)

29 Sadot E, Reidy-Lagunes DL, Tang LH, Do RK, Gonen M, D'Angelica MI, DeMatteo RP, Kingham TP, Groot Koerkamp B,
Untch BR, et al. Observation versus resection for small asymptomatic pancreatic neuroendocrine tumors: a matched case-control study. Annals of Surgical Oncology 201623 1361-1370. (doi:10.1245/s10434015-4986-1)

30 Bettini R, Boninsegna L, Mantovani W, Capelli P, Bassi C, Pederzoli P, Delle Fave GF, Panzuto F, Scarpa A \& Falconi M Prognostic factors at diagnosis and value of WHO classification in a mono-institutional series of 180 non-functioning pancreatic endocrine tumours. Annals of Oncology 200819 903-8. (doi:10.1093/ annonc/mdm552)

Received in final form 12 October 2017 Accepted 25 October 2017 (c) 2017 The authors Published by Bioscientifica Ltd

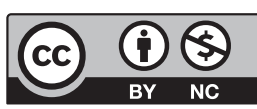

This work is licensed under a Creative Commons Attribution-NonCommercial 4.0 International License. 